\title{
Johann Ulrich von Bilg(u)er* (geb. 1720 in Chur, gest. 1796 in Berlin)
}

Ein Beitrag zur Lebensgeschichte des berühmten Kriegschirurgen

\author{
Von HansJakob Müller, Chur
}

Bilgers Bedeutung für die Entwicklung der Chirurgie ist heute kaum noch umstritten $(3,4,6,7,8,10)$, stellten doch seine Interventionen gegen die damals unter dem Einfluß vor allem der französischen Chirurgen zu häufig ausgeführten Amputationen einen entscheidenden Wendepunkt in der Kriegschirurgie dar, was ihm den Beinamen "Vater der konservativen Chirurgie» eintrug. Die aufsehenerregende Schrift Bilgers, die besonders gegen die Amputationsfreudigkeit französischer Chirurgen bei Schußwunden gerichtet war, erschien erstmals als Dissertation zur Promotion an der Universität Halle/Saale: Dissertatio de membrorum amputatione rarissime administranda, aut quasi abroganda, 1761, mitten im Siebenjährigen Krieg; eine deutsche Ausgabe durch den Verfasser selbst, Berlin 1761, eine französische mit Bemerkungen von Tissot, Paris 1764, eine englische, London 1764, eine holländische, Nimwegen 1771, eine spanische, Madrid 1782. Von seinen Biographen wird bedauert, daß nicht mehr über seine Person und sein Privatleben überliefert ist, denn Baldinger (1), der einzige unter ihnen, der geltend machen kann «Dank sey es dem Himmel, daß ich das Glück genoß, Herrn Bilguer persönlich kennenzulernen, ein Zeuge von der glücklichen Ausübung seiner Kunst zu seyn und mit seiner Freundschaft beehrt zu werden, als wir zu gleicher Zeit in Torgau unsere Posten zu verwalten uns aufhielten ", geht nicht näher darauf ein. So schreibt Albert KöHLER (6), der die einschlägige Literatur durchgesehen und die meisten Werke Bilgers selbst gelesen hat, resigniert: «Von Bilguers Privatleben wissen wir wenig oder nichts, aus einzelnen Stellen, z. B. in den Nachrichten über die Hypochondrie, könnte man schließen, daß er verheiratet war. Genaueres ist nicht bekannt.» Wir haben nun versucht, mehr über das Leben dieses interessanten Menschen, der uns in seinen Werken als farbige Persönlichkeit imponiert, zu erfahren.

Der Generalchirurg der preußischen Armee geht aus dem alten Churer Geschlecht der Bilger hervor, das sich nach Ulrich Campell (5), dem Senior der rätischen Geschichtsschreibung, auf den ehemaligen Prior des Praemonstratenser Klösterleins St. Jakob zu Klosters im Prättigau Bartholomeus Bilger zurückführen läßt, der 1525 das Ordensgewand ablegte, sich verheiratete und nach Chur zog $(2,3,7)$. Hier sind die Bilger auch erstmals 1527 als Bürger aufgeführt. und lassen sich in den Stadtakten bis ins frühe 19. Jahrhundert verfolgen. Sie

\footnotetext{
* Bilguer $=$ französische Schreibweise gemäß damaliger Sitte am preußischen Hof.
} 
übten neben anderen Berufen, wie übrigens Bilgers Vater JoнANn Luzıus, vor allem das Schererhandwerk aus und gehörten somit gemäß der Churer Zunftordnung der Pfisterzunft an (7).

Baldinger (1) gibt als Bilgers Geburtsdatum den 1. Mai 1720 an, und die späteren Biographen scheinen von ihm dieses Datum übernommen zu haben. Im Kirchenbuch der St.-Martins-Kirche ist jedoch «an den 21. Aprellen» 1720 ein Hans Ulrich Bilger als Sohn von Meister Luzi Bilger und Anna Gampser (in) eingetragen, dem Daniel Abiss und Obrist M.v. Salis Paten waren (7). Diese Eintragungen wurden vom jeweiligen Kirchenvorsteher vorgenommen und gelten als sehr zuverlässig. Auch die Gampser zählten zu den Churer Bürgern, nachdem sie einst vom Rheintal her in die durch Feuersbrünste und Seuchen entvölkerte Stadt eingewandert waren.

Nach Watzka (11) heiratete Bilger 1742 in Heslach bei Stuttgart die Tochter eines Regimentschirurgen Johanne Friederike Mögling (Bener: Moeglin [2]). Dieser Ehe scheinen eine Reihe von Kindern entsprossen zu sein, denn aus einem Immediatbericht vom 17.Juni 1786 (erhalten im Deutschen Zentralarchiv in Merseburg) erfahren wir, als Bilger um die Gewährung eines Urlaubes von mehreren Wochen bittet, um seine Tochter zu besuchen: «Ich versäume hier nichts, das Publikum hat sich seit meiner unverschuldeten Entehrung gänzlich von mir abgewandt und giebt mir nichts mehr zu verdienen. Ich muß aber ein schuldloses Opfer meines unglücklichen ältesten Sohnes seyn, der 16 Jahre bei seiner Königlichen Hoheit dem Prinzen Heinrich als Secretaire gedienet, da er aber um eine gewissere Versorgung angehalten, so wurde er in höchster Ungande entlassen, und diese Ungnade trift mich, eine rechtschafene Frau und 13 Kinder und Kindes-Kinder, wenn Sich Ew. Königliche Magestät nicht über eine rechtschafene Familie allergnädigst erbarmen.» Ủber die Ernennung bzw. Entlassung von Bilgers Sohn ist nichts erhalten.

Es ist mehrfach aufgefallen $(3,4,6,7,10)$, daß es bereits im frühen Alter stiller um Bilger wurde. Schon in der Einleitung zum Taschenbuch für Wundärzte vom Jahre 1783, wo Richter, Schmucker, Pallas und Voitus als Ärzte genannt werden, "auf die jeder Deutsche mit Ehrfurcht und Entzücken blickt», wird er nicht genannt, obgleich in demselben Heft seine Lebensbeschreibung zu finden ist. Als 1786 der erste Generalchirurg Johann Leberecht Schmugker starb, rückte nicht Bilger, sondern der dritte Generalchirurg Johann Christian Theden an dessen Stelle vor. Auch in den damaligen Deutschen Zeitungen ist keine Notiz über eine Feier z. B. zu seinem 70. Geburtstag zu finden. Leider liegen Dokumente über Bilgers Erhebung in den Adelstand, die 1794 erfolgt sein soll, nicht mehr vor.

Bener (2) führt persönliche Mitteilungen aus dem Heeresarchiv Potsdam als Quellen zu seiner Kurzbiographie über Bilger an. Dieses wurde im letzten Weltkrieg bei einem Bobenangriff völlig zerstört.

Im Deutschen Zentralarchiv in Merseburg fand man jedoch noch zwei weitere Immediatberichte auf (Per. 96, Geheimes Zivilkabinett). Im ersteren vom 23. Sep- 
tember 1763 bittet Bilger zusammen mit dem Generalchirurgen SchмücKE um die Entsendung von zwei Feldscherern zu Studienzwecken nach Frankreich; im zweiten vom 21. Juli 1782 bittet er um Gewährung einer Audienz, um dem König Vorschläge zu unterbreiten, «daß künftighin die Feldlazarethe mit dem halben Geld und Aufwand besser besorgt und der Mortalität Grenzen gesetzt werden.»

Glücklicherweise wurde uns durch eine Churer Familie ein kaum noch lesbarer Brief Bilgers an seinen Bruder Antistes* Daniel Bilger, der vom 16. Februar 1788 datiert, bis heute erhalten $(2,7)$. Er ist fälschlich an Monsieur Bilger, Doyen de l'Eglise cathédrale à Coire adressiert, während sein Bruder als Pfarrer der evangelischen St.-Martins-Kirche vorstand (9). Bilger schreibt:

«Monsieur et mon très cher Frêre,

Ich will hoffen und wünschen, daß dieses Schreiben, mein liebster Bruder dich und die Deinigen gesund und wohl antreffen werde. Meine ganze Familie nebst mir befinden uns Gott lob gesund und wohl und haben diesen schönen Sommer in Ruhe und Zufriedenheit zubringen können. Indessen befürchte auf künftiges Frühjahr einen Marsch nach Pohlen oder gar an die Russische Grenze ungeachtet der Kayser und die Russen gegen die Türken nichts ausrichten sondern in sonderheit der Kayser immer zurückweicht und das schöne Ungarn zerstören lassen muß. Wir sehen das gerne und wünschen, daß so wohl Rußland als Österreich so mächtig gemacht werden, daß sie in $30 \mathrm{Jahren}$ sich nicht erholen können und also künftig hin dem übrigen Europa nicht ferner hin Grenze vorschreiben. Wir halten uns immer parat, und ich habe vom Kriegsdepartement den Befehl erhalten die Feldlazaretgerätschaften auf 200000 Mann genau zu bestimmen damit sie können angeschaft werden. Seine Mag. der König waren auch so gnädig mir von diesem Monat an eine jährliche Zulage von 500 Rth. zu accordieren, so daß ich jezo alle Tage den Extraverdienst 4 rth oder 8 Pündner Gulden zu verzehren habe. Indessen ist hier die Lebensart kostbar, und es bleibt mir von diesem reichlichen Gehalte wenig übrig. Warum wendet sich die Republik wegen deren Valteliner Streitigkeiten nicht an unsern König, da der Kayser nicht mehr furchtbar und er uns sehr gute Worte gibt, so würde eine Insinuation unsererseits den größten Nuzen eräußern. Die Stände dürften mir diese Geschäfte auftragen, ich bin denen Ministern des auswäertigen Departementes gut betraut, und ich würde zum Vergnügen meines Vaterlandes gewiß was ausrichten. Das Pädagium regnum in Halle wird sehr gerühmt seit der Professor Niemayer Zoologie hält in gedruckter Anweisung, worin die Lehrstunden und alle Disziplinen genau bestimmt, aus Zürich müßte sie, liebster Bruder erhalten können. Vorrichtes Frühjahr hatte ein mäßiges Podagra, ich messe die Schuld daran Ungarischem Wein bey, den ich bey

* Antistes $=$ Vorsteher der reformierten Geistlichkeit in Zürich, Basel, Graubünden, Thurgau. 
einem Polnischen Grafen habe öfters trinken müssen. Ich habe ein großes Verlangen und Zutrauen zum Valteliner und wünsche, liebster Bruder, daß du mir ein Paar Legel zur Probe, noch in einem Verschlag eingemacht, übersenden möchtest, der Wein müßte vom vorigen Jahr und stark sein, das ist, viel Corps haben, denn der feine Wein würde verrauchen, und die rote Farbe zu Boden sezen, wie es mir mit dem Veraguthschen Wein ergangen, der gar nicht zu trinken war, ich will die Auslagen mit Freuden bezahlen. Der Wein muß aber im Herbst oder Frühjahr abgesandt werden, sonst verdirbt er unterwegens. Champagner darf ich nicht trinken, der Burgunder ist zu hizig, und die übrigen französischen Weine außer Chateau Margot schmecken nicht. Lebt der Wachtmeister Wehrli nicht mehr, er hat versprochen lebendige Pernissen* zu überbringen, er würde mit diesen Vöglein sein Glück beim König machen. Meine Famille nebst mir embrassieren dich und die Deinigen herzlich und verharren in brüderlicher Liebe.

Monsieur et mon tres cher Frêre

Berlin, 16 $6^{\text {h }}$ Febris 1788

votre fidel frêre

JU Bilguer

Dieser wundervolle Brief spricht für sich! Wir finden nicht nur bestätigt, daß Bilger mit dem Messer viel geschickter umzugehen wußte als mit der Feder, sondern auch, daß er, der sich vor allem in seinem Werk über die Hypochondrie für eine einfache, fast karge Lebensführung einsetzt, auf die weltlichen Genüsse nicht verzichten konnte und daß die in den Büsten Berlinscher Gelehrten und Künstler mit Devisen (Berlin 1787) gegebene Charakterisierung als «Ein Mann, der auch die Bestandtheile des Rheinweins gut kennt, so wie er sich auch auf den böhmischen Ochsenhandel verstand, und die Prager Tischlerarbeit zu schätzen wußte» recht zutreffend sein muß. Weiter hat Bilger herausgefunden, was heute in jedem Lehrbuch der Medizin zu lesen ist, daß gerade der Champagner und der Burgunderwein Gichtanfälle provozieren, während andere Weine individuell unterschiedlich gut vertragen werden, daß also neben dem Alkohol noch irgendwelche Bukettstoffe in den Harnsäurehaushalt eingreifen können. Bilgers Brief ist aber auch ein wertvolles Zeitdokument für die preußische Geschichte. Wir entnehmen seinen Schilderungen, daß er neben seinen beachtenswerten chirurgischen Fähigkeiten ein Mann mit großem politischem Einfluß war, der sich seiner Heimat, die große Sorgen um ihr Untertanenland Veltlin hatte, als Vermittler zum Habsburgischen Kaiserhof anbieten durfte. Bilger starb am 6. April 1796 in Berlin.

* Pernissen $=$ Steinhühner. 


\section{Literaturverzeichnis}

1. Ernst Gottfried Baldinger, Biographien jetztlebender Ärzte und Naturforscher in und außer Deutschland, 1768, Abschnitt XI, S. 91-102.

2. Gustav Bener, Ehrentafel Bündnerischer Naturforscher, 1938, S. 19-21.

3. Heinrich Buess, Johann Ulrich Bilger, Praxis 19 (1946) 292-294.

4. Cladudia Farner, Der Bündner Chirurg Johann Ulrich Bilguer und sein Werk über die Hypochondrie, Bündner Monatsblatt 1963, 281-330.

5. Fritz Jecklin, Urbar der Propstei St. Jakob im Prätigau, 1910, S. 4, 5, 7.

6. Albert Köhler, Die Kriegschirurgen und Feldärzte Preußens und anderer deutscher Staaten in Zeit- und Lebensbildern, 1899, S. 186-197 (I.Teil).

7. HANSJaKoв Müller, Über den Churer Kriegschirurgen Johann Ulrich Bilger, Bündner Jahrbuch 68 (1967) 74-82.

8. Henry Nigst, Johann Ulrich Bilgers physikalisch-mechanische Theorie der Contrafissuren, Schweiz. med. Wschr. 1947, 758-759.

9. Michael VAlär, Die evangelischen Geistlichen an der Martinskirche in Chur, 1919, S. 98-101.

10. KarL Vogeler, Johann Ulrich Bilguer und der Streit um die Amputation im 18. Jahrhundert, Münchener med. Wschr. 1929, Nr. 18, S. 750-754.

11. Maximilian WatzKa, Johann Ulrich v. Bilguer, Neue deutsche Biographie, 1955, 2. Band, S. 236.

Mitteilungen von Dr. WeISER vom Deutschen Zentralarchiv Merseburg.

Brief Bilgers vom 16. Febris 1788, Privatbesitz von Herrn Daniel Hatz, Arbon. 